\title{
A Comparative Study of Operating Systems: Case of Windows, UNIX, Linux, Mac, Android and iOS
}

\author{
Akinlolu Adekotujo \\ PhD Student \\ Computer Science Dept., \\ Lagos State University, \\ Nigeria
}

\author{
Adedoyin Odumabo \\ PhD Student \\ Computer Science Dept., \\ Lagos State University, \\ Nigeria
}

\author{
Ademola Adedokun \\ PhD Student \\ Computer Science Dept., \\ Lagos State University, \\ Nigeria
}

\author{
Olukayode Aiyeniko \\ Lecture II \\ Computer Science Dept., \\ Lagos State University, \\ Nigeria
}

\begin{abstract}
Varieties of operating systems (OS) have emerged over the years having different features and functionalities. Understanding the functionalities of each OS guides users' decisions about the OS to install on their computers. In view of this, the comparative analysis of different OS is needed to provide details on the similarities and difference in recent types of OS vis-à-vis their strengths and weaknesses. This paper focus on the comparative analysis of Windows, Unix, Linux, Mac, Android and iOS operating systems based on the OS features and their strengths and weaknesses. A qualitative analysis of six different operating systems and result showed that Windows 10 had 0.04 malware file present while Windows 7 machine was 0.08 . Higher percentage of mobile malware target Androids than iOS. Windows 10, Linux, UNIX and Mac OS are more secured and reliable. Windows and Android are more popular, user-friendly, easy to use and allow more application program than Mac OS. Linux and Android are free while Windows is moderately costly and Mac OS is very costly. Except for Mac and iOS others allow compatibility. Windows 10 and Mac OS integrated firewall. Windows and Android tend to be the most widely used especially the newest versions. It is because they are affordable, secure, reliable, compatible and user friendly. This study helps to provide some guides to both end-users and developers guiding them in taking decisions about operating systems that are most suitable for them.
\end{abstract}

\section{General Terms}

Operating System

\section{Keywords}

Operating System, Windows, Linux, Mac, UNIX, Android, iOS, Comparative Analysis

\section{INTRODUCTION}

Operating System (OS) is software that manages and controls the main computer hardware, the hardware peripherals and software resources, so also the users. It also offers the platform and support for application programs and acts as an interface between the computer user, programmers inclusive, and the computer hardware [1]. Applications software like word processors, spreadsheets, databases, and other dedicated applications that businesses need, run on a given OS platform.

Operating systems provide standard services for processes implementation such as storage, deadlock, scheduling and other processes. It also provides a programming environment that enables a user to write and execute programs in a much convenient and efficient way. Every computer system including desktops, laptops, tablets, supercomputers, hand- held and even video game consoles use some type of operating system. There are numerous types of operating systems in today's ICT world. Mac Operating System designed and owned by Apple Inc., Windows by Microsoft Inc., Linux by Community, likewise Android by Google Inc. and others.

Varieties of Operating Systems have emerged over the years having different features and functionalities. Understanding the functionalities of each OS guides users' decisions about the OS to install on their computers. In view of this the comparative analysis of different OS becomes inevitable. Thus the need arises for a comparative analysis that will give an overview of the similarities and difference in different types of OS with the view to presenting and mapping the features of the OS with various user services.

This paper presents a comparative study of six (i.e. Windows, Linux, Mac, UNIX, Android and iOS) operating systems based on the OS features and their strengths and weaknesses.

The paper is structured as follows: Section 2 presents the review of related works while Section 3 presents the comparative analysis of Windows, UNIX, Linux, Mac, Android, and iOS. Section 4 presents merits and demerits of Windows, UNIX, Linux, Mac, Android, and iOS. Deductions are presented in Section 5 and Conclusion is presented in Section 6.

\section{REVIEW OF RELATED WORKS}

Several research works had been carried out on operating systems used on desktop computer systems and mobile devices. Summary of the existing works is presented in this section.

Lin and Ye in [2] investigated the smartphone OSs market in a uniform ecosystem framework. They compared major companies like Nokia, RIM, Apple and Microsoft. The result showed that the companies used smartphone OS as a business unit and as opportunity for new business. Similarly in [3], the authors compared various operating systems (OSes) for developing WSN applications such as TinyOS, Contiki, and LiteOS. Several issues were considered amongst which are: memory requirement, process management and scheduling, kernel model, reliability etc. Moreover, features such as Networking Support, Real-Time Guarantee, Language Support, Multi-Threading Support, File System, Platform Support, and Simulator for comparison of these OSes were discussed. Strengths and weaknesses of the operating systems were equally identified. The significance of this work is that, the OS developers will know what had been done on existing OSes, and the OS users will know the various features of 
existing sensor network OSes, so as to enable them select the most suitable for their application.

Mudiraj in [4], did comparative study of booting paradigm of Windows, Linux and Mac operating system. This experimental study gave an idea about the Booting Process similarities and difference in these three operating systems. The result of experiment showed that every operating system considered have same common POST step processed during the booting process. Mac has its own mechanism such as BootROM, which has its own operating system boot loader called BootX or Boot.efi. It is the only operating system that does not support any BIOS mechanism while booting it.

In [5], a review of various mobile technologies such as $1 \mathrm{G}$, $2 \mathrm{G}$ and $3 \mathrm{G}$ with different mobile $\mathrm{OS}$ was carried out. The authors compared Symbian OS, Android OS, BlackBerry OS, iOS and Windows Phone based on Vendor, Programming Language and Application Store. The result showed that iOS has more features and require less code. They established that android and apple are growing faster in the market. Similarly comparison of two android and iOS was carried out in [6] with emphasis on security. The security features used for comparisons are encryption approach, memory randomization, data storage format, application sandboxing, and built-in antivirus. Results showed that iOS is more secured than android OS. Also, other security issues about users' data are identified. Furthermore, Okediran et. al., did a comparative analysis of different technological platforms in [7]. The Smartphone OSs reviewed were Android-Google, iOS-Apple, Blackberry OS, Windows Phone-Microsoft, web OS and Symbian OS-Nokia. The result showed android as the most flexible and dynamic mobile operating system.

In 2014, a user model for OS design based on UX to aid product designers to find the connection between user perception and UX was presented in [8]. The empirical study was done to compare the dominant OSs in tablets: Windows 8, iOS 6, and Android 4.2 with the major aspects to establish satisfactory or unsatisfactory UX. The paper used users' data, such as demographic factors, usage frequency, personal character, personal aesthetic, and voluntariness of use to predict the UX. The results showed that the iOS 6 holds a satisfactory in terms of architectural support and favorable brand image, Android 4.2 holds a satisfactory in terms of architectural support and functional performance and Windows 8 holds a satisfactory in terms of functional performance but the OS is unclear, hard to use, and learn, inadequate GUI support which make it unsatisfactory. Also [9] discussed the android architecture, its operating system and main features. The work compared Android with different OS like iOS (Apple), Blackberry OS (RIM), and Symbian (Nokia). From their analysis, they concluded that Android is better than all other operating systems. Conversely, Android is an open source OS, had some limitations such as malware attacks like virus, spyware, worms etc.

Computer system had been used to achieve several computer crimes which include hacking/cracking, computer viruses, network intrusion etc. Recently, digital forensic has been used to identify any malicious activity in operating system. The research reported in [10] explained the fundamentals of Windows7 registry and its structure and Ubuntu12 file system; a comparative analysis of the Windows7 registry and Ubuntu12 file systems of various activities based on auto run program, recently accessed documents, application settings, malware activity, login \& shutdown activity, network accessed, and its relations to the digital forensic. The aim of this work was to compare Windows 7 and Ubuntu 12 operating systems in forensic investigation of user activities. Digital forensic technique was adopted. Windows 7 operating system keeps track of information in the registry, which helps to discover the kind of activity performed by the user and kind of infection and intruder when analyzed. Ubuntu uses text files in system configuration which help in investigation of action and malicious activity tracking.

The work presented in [11] identified the key factors affecting the choice of OS (Android and iOS) customers, and the demographic effect on their choice. The analysis showed that age group and applications available in the app store are significant in influencing the choice of OS. This study revealed that among smartphone users, Android and iOS are highly preferred. Android is preferred by customers because of its high customized features, user interface and free availability apps while iOS is a special mobile operating system that works only on Apple devices and well known for its high security features. It is recommended that Android should enhance its security features and battery life span; and iOS should increase its free available apps and develop widget support. Also in [12], the authors compared the operating systems of mobile devices such as Android, iPhone OS, BlackBerry, Windows Mobile, Symbian with the following features concurrency, memory use network and security. The result showed that each operating system have strengths and weaknesses, therefore it is certainly impossible to say which operating system is the best. Apple placed unnatural restrictions on their iOS devices while the others have no difficulty in running various applications at the same time. Android is the only free open source operating system. In terms of restricted memory capacity, all operating systems have different technologies to deal with it more but BlackBerry and Android OS deals less with restrictions. All operating systems have restrictions in regard of automatically connecting to $\mathrm{Wi}-\mathrm{Fi}$ or Bluetooth network but Windows Mobile and Android 2.0 did not have any restrictions. In term of security, BlackBerry and Android OS both run applications in sandboxed virtual machine but other operating systems had complications for signing applications. Android and iPhone OS are nowadays leading the business market.

In 2019, Enterprise Operating System (EOS) was presented in [13]. The goal was to develop a universal EOS (UEOS) model. The review of the Viable Systems Model (VSM), Le Moigne general system theory, the nine level model (NLM), and enterprise engineering (EE) concepts was done and from which the first elementary functional model of UEOS was developed. Three perspectives of active object such as functional, ontological, evolutionary were identified from Le Moigne's theory, memory facilitating the operational and the management/decision enterprises subsystems were identified from the NLM and relevant contributions from GOD theory, the Organizational Self Awareness (OSA) concept, and rigorous tools as DEMO were identified from EE. Also, contributions were gotten from complex theories, principally the concept of "bounded instability" and the strategies to maintain a system in "edge of chaos". The research was in its initial phase, therefore there is need for valuable feedback from research communities to help evolving the first functional elementary UEOS model, into a complete and comprehensible one.

In recent years, there were increased in the development of Internet of Things (IoT) applications to control remote systems especially in industrial engineering by interlinking a large number of devices. The core idea of the IoT is to make available a network of physical objects having embedded 
technology accessible through the Internet. This technology permits these objects to collect and transmit data between diverse nodes. The authors in [14] proposed a new autonomous IoT model predictive controller that uses lowcost hardware and free software for a class of linear multiagent system even when network is imperfect. It goal is to improve the network service quality in the industrial field. This method is applied to a mobile robot over embedded leader-followers wireless networked architecture using Internet of Things Operating System running on STM32 and radio frequency communication shields over the User Datagram Protocol. To implement the enactment of the predictive control algorithm, the User Datagram Protocol was used because of the high number of packet losses in the communication network. Therefore, analysis of Internet of Things technology among agents was carried out joined with a network predictive control scheme against packet loss, limited bandwidth and attack links. The Experimental results showed the effectiveness of this method in perturbation attenuation, reference tracking, and security link even in the case of imperfect network. The proposed experiment solved the problem of data losses in the communication network.

Table 1. Quality Comparison of Windows, UNIX, Linux, Mac, Android and iOS based on Features and Functionalities
Also, it improved the quality of monitoring capability in the diverse wireless network settings for remote control automation systems.

\section{COMPARATIVE ANALYSIS OF WINDOWS, UNIX, LINUX, MAC, ANDROID, AND IOS}

In this paper, emphasis is to carry out a comparative study of the following operating systems: Windows, UNIX, Linux, Mac, Android and iOS. Issues of concern are: Computer Architecture Supported, Target System Type, File System Supported, User Friendly for Lay Users, Integrated Firewall, Security Threats, Shell Terminal, Kernel Type, Reliability, and Compatibility. Also, the advantages and limitations of each of the operating systems were listed. The comparison of the operating systems based on features and functionalities is presented in Table 1.

\begin{tabular}{|c|c|c|c|c|c|c|}
\hline & Windows & Linux & Mac & UNIX & Android & iOS \\
\hline Manufacturer & Microsoft Inc. & $\begin{array}{l}\text { Linux is developed as } \\
\text { open source OS under } \\
\text { the GNU project by } \\
\text { the Originator, Linus } \\
\text { Torvalds and many } \\
\text { others. }\end{array}$ & $\begin{array}{l}\text { Apple Inc. } \\
\text { for their } \\
\text { Macintosh } \\
\text { line of } \\
\text { computer } \\
\text { systems. }\end{array}$ & $\begin{array}{c}\text { Three biggest } \\
\text { distributions are Solaris } \\
\text { running (Oracle), } \\
\text { AIXon (IBM) \& HP- } \\
\text { UX Hewlett Packard. } \\
\text { And Apple Makes } \\
\text { OSX, an Unix based } \\
\text { OS }\end{array}$ & $\begin{array}{l}\text { Open source } \\
\text { OS designed } \\
\text { \&developed } \\
\text { by Android } \\
\text { Inc. Google is } \\
\text { now the } \\
\text { current owner }\end{array}$ & $\begin{array}{l}\text { Apple Inc. } \\
\text { closed, with } \\
\text { components } \\
\text { that are } \\
\text { source openly }\end{array}$ \\
\hline $\begin{array}{c}\text { Development } \\
\text { and } \\
\text { Distribution }\end{array}$ & $\begin{array}{l}\text { Developed and } \\
\text { distributed by } \\
\text { Microsoft. }\end{array}$ & $\begin{array}{c}\text { Linux is Open } \\
\text { Sourced and } \\
\text { distributed by various } \\
\text { vendors. }\end{array}$ & $\begin{array}{l}\text { Mac OS was } \\
\text { designed } \\
\text { only to be } \\
\text { deployed by } \\
\text { Apple } \\
\text { Computers. }\end{array}$ & $\begin{array}{l}\text { Unix system has } \\
\text { various flavors, most of } \\
\text { which are developed by } \\
\text { AT\&T with other } \\
\text { commercial vendors } \\
\text { and non-profit orgs. }\end{array}$ & $\begin{array}{l}\text { OHA (Open } \\
\text { Handset } \\
\text { Alliance) }\end{array}$ & $\begin{array}{l}\text { Apple Inc. } \\
\text { developed } \\
\text { and } \\
\text { distributed } \\
\text { iOS }\end{array}$ \\
\hline $\begin{array}{c}\text { Computer } \\
\text { Architecture } \\
\text { Supported }\end{array}$ & $x 86, x 86-64$ & $\begin{array}{c}\text { x86, x86-64, } \\
\text { PowerPC, SPARC, } \\
\text { Alpha, Others }\end{array}$ & $\begin{array}{c}68 \mathrm{k}, \\
\text { PowerPC }\end{array}$ & $\begin{array}{c}\text { Available on PA-RISC } \\
\text { and Itanium machines. } \\
\text { Solaris also available } \\
\text { for x86/x64 based } \\
\text { systems. OSX is } \\
\text { PowerPC }(10.0- \\
10.5) / x 86(10.4) / x 64 \\
(10.5-10.8)\end{array}$ & $\begin{array}{l}\text { Android-x86 } \\
\text { powered by } \\
\text { AMD and } \\
\text { Intelx86 } \\
\text { processors. }\end{array}$ & ARM \\
\hline $\begin{array}{c}\text { Target } \\
\text { System Type }\end{array}$ & $\begin{array}{l}\text { Workstation, } \\
\text { Personal Computer, } \\
\text { Media Centre, } \\
\text { Tablet PC, } \\
\text { Embedded. }\end{array}$ & $\begin{array}{l}\text { Desktop/Server } \\
\text { Depends on } \\
\text { Distribution }\end{array}$ & $\begin{array}{l}\text { Workstation, } \\
\text { Personal } \\
\text { Computer, } \\
\text { embedded }\end{array}$ & $\begin{array}{l}8086 \text { UNIX system, } \\
\text { PDP-11/70 system }\end{array}$ & $\begin{array}{l}\text { Consumer, } \\
\text { Enterprise, } \\
\text { education }\end{array}$ & $\begin{array}{l}\text { Smartphone, } \\
\text { music system } \\
\text { player, Tablet } \\
\text { system/ } \\
\text { computer }\end{array}$ \\
\hline $\begin{array}{l}\text { File System } \\
\text { Supported }\end{array}$ & $\begin{array}{c}\text { NTFS, FAT \& } \\
\text { exFAT with ISO } \\
\text { 9660; UDF, } 3^{\text {rd }} \\
\text { Party driver that } \\
\text { supports file system } \\
\text { ext2, and ext3, } \\
\text { ReiserFS, and HFS }\end{array}$ & $\begin{array}{c}\text { ext2, ext3, } \\
\text { ex4, ReiserFS,FAT, } \\
\text { ISO 9660,UDF, NFS, } \\
\text { and others. }\end{array}$ & $\begin{array}{c}\text { HFS }+ \text {, HFS, } \\
\text { MFS (Mac } \\
\text { OS } 8.0 \text { and } \\
\text { before) AFP, } \\
\text { with ISO } \\
\text { 9660, FAT, } \\
\text { UDF }\end{array}$ & $\begin{array}{l}\text { jfs, gpfs, hfs, hfs+, ufs, } \\
\text { xfs, zfs format }\end{array}$ & Ext4 & HFS+, FTP \\
\hline $\begin{array}{l}\text { User Friendly } \\
\text { for Lay Users }\end{array}$ & Very User Friendly & $\begin{array}{c}\text { Depends on } \\
\text { Distribution. More } \\
\text { friendlier to users }\end{array}$ & $\begin{array}{l}\text { Very User } \\
\text { Friendly }\end{array}$ & $\begin{array}{l}\text { Unix is user-friendly. } \\
\text { It's just choosy about }\end{array}$ & $\begin{array}{l}\text { Very User } \\
\text { Friendly }\end{array}$ & $\begin{array}{l}\text { Very User } \\
\text { Friendly }\end{array}$ \\
\hline
\end{tabular}




\begin{tabular}{|c|c|c|c|c|c|c|}
\hline & & than Unix & & who its friends are & & \\
\hline $\begin{array}{c}\text { Integrated } \\
\text { Firewall }\end{array}$ & Windows Firewall & $\begin{array}{l}\text { Chroot capability- } \\
\text { based security, [s 5] } \\
\text { seccomp, SELinux }\end{array}$ & $\begin{array}{l}\text { Application } \\
\text { Firewall }\end{array}$ & IPFilter & iptables & $\begin{array}{l}\text { Firewall-IP } \\
\text { for iOS }\end{array}$ \\
\hline $\begin{array}{l}\text { Security } \\
\text { Threats }\end{array}$ & Huge & Negligible & Negligible & Mild & Negligible & Negligible \\
\hline $\begin{array}{c}\text { Shell } \\
\text { Terminal }\end{array}$ & CMD & $\begin{array}{l}\text { Bash shell powerful } \\
\text { shell with many } \\
\text { features }\end{array}$ & BASH & $\begin{array}{l}\text { Originally the Bourne } \\
\text { Shell. Now it's } \\
\text { compatible with many } \\
\text { others including BASH, } \\
\text { Korn \& C. }\end{array}$ & Mosh & Blink Shell \\
\hline Kernel Type & Hybrid & $\begin{array}{l}\text { Monolithic with } \\
\text { modules }\end{array}$ & $\begin{array}{l}\text { Monolithic } \\
\text { with } \\
\text { modules }\end{array}$ & $\begin{array}{l}\text { Monolithic with } \\
\text { modules }\end{array}$ & Linux kernel & $\begin{array}{l}\text { XNU kernel } \\
\text { of Darwin }\end{array}$ \\
\hline Reliability & Great & Great & Greatest & Greater & $\begin{array}{l}\text { Could be } \\
\text { unstable }\end{array}$ & $\begin{array}{l}\text { More than } \\
\text { Android }\end{array}$ \\
\hline Compatibility & $\begin{array}{l}\text { Can coexist on local } \\
\text { networks with } \\
\text { Windows, BSD, } \\
\text { Macs, and other } \\
\text { Unix-like systems. } \\
\text { More compatible. }\end{array}$ & $\begin{array}{l}\text { Linux has few } \\
\text { programs and games } \\
\text { like Windows. But is } \\
\text { more compatible and } \\
\text { scalable than Unix }\end{array}$ & $\begin{array}{c}\text { Only few } \\
\text { programs } \\
\text { will run on } \\
\text { Mac }\end{array}$ & $\begin{array}{l}\text { Unix does not have as } \\
\text { many programs and } \\
\text { games as Windows }\end{array}$ & $\begin{array}{l}\text { Better than } \\
\text { iOS }\end{array}$ & $\begin{array}{c}\text { Compatibility } \\
\text { is fair }\end{array}$ \\
\hline
\end{tabular}




\section{MERITS AND DEMERITS OF THE OPERATING SYSTEMS: WINDOWS, UNIX, LINUX, MAC, ANDROID, AND IOS}

\subsection{Windows Operating System}

Windows Operating System was introduced into the market in the year 1985, and as a robust and comprehensive kind of software, has almost $90 \%$ market share over and above other operating system [15]. With its great and dominance presence in commercial buildings, industrial facilities, as well as its obvious presence as home computers. Although this assertion is believed not to be so again as a result of overwhelming peoples interest in open source operating systems.

The Microsoft Operating System as a family of Microsoft windows was created as a graphical layer over that of old MS dos with its root from MS DOS Command line and this it retains till date with DOS Box command prompt that is cmd.exe. [16]. Original Windows NT core happens to be the first to take shape in OS/2 operating system upon which modern versions are dependent. 32 and 64-bit AMD and Intel systems accommodate Windows OS, DEC Alpha, PowerPC architectures Windows OS, and MIPS is also comfortable with recent versions, likewise low and mid-range servers. Database and web servers also allows Windows operating system to use them. In recent years, Microsoft has proofed significant with marketing and with its finance to establish that Windows interoperability is not in doubt and that it has all that it takes as a platform to run any enterprise application.

\subsubsection{Merits of Windows $O S$}

i. Technical/Maintenance support: Support is made available either online or offline because of its general acceptability by so many users.

ii. Compatibility: Windows accommodates almost every applications, game works and different types of drivers.

iii. Enormous quantity of functions: Getting use to Windows, one would realize that there are many functions one can do almost anything quite easily with when call up.

\subsubsection{Demerits of Windows OS}

i. Viruses: Need to purchase an antivirus programs that needs to be activated frequently, and this can be done on Auto or Manual mode, although free antivirus exist but with limitations.

ii. Slow: Windows operating system, particularly Vista and Windows 7 needs a lot of system resources like registers, cache, main memory, processor, disk space, and this makes the system runs slower.

iii. Price: The cost of purchasing Windows operating system is high and very few users can afford it and this necessitate cracking and makes pirated software version available.

\subsection{UNIX Operating System}

UNIX happens to be one of the very few oldest of all operating system in recent time of ICT world that is still generally and widely used and available till date, as none conspicuous operating system but its somehow secret in its operation and interface design, it is primarily designed for the use by very large enterprise computing systems. It happens to be one of the common operating system that is run by servers and other computers that form the large bulk of the Internet.

One might never use UNIX on local PC, but indirect use is obvious in one form or another, every time one log on to the internet. Very few users runs UNIX on their personal systems, and a lot of different versions of UNIX operating system are available for UNIX PC, and one of such is "UNIXy" which so many users have installed on desktop machines. There are so any different types and features basic UNIX interface; Linux, with its different version turn out to be the most common and popular for personal computer platform.

Setting up a UNIX OS can be difficult and it requires some knowledge to operate, but it is stable and robust, and efficient with system resources. UNIX OS uses the "UNIX file system". However, most file systems used by UNIX OS are impartially similar, but different uniquely from of other operating systems file systems, such as DOS or Windows. The trademark UNIX® is been owned by the Open Group, Only PCs fully compliant with and certified to the Single UNIX Specification qualify as "UNIXR", others are referred to or known as "Unix system-like" or "Unix-like".

Between later and early part of 1970 and 1980 respectively, UNIXs way in academic circles led to large scale acceptance of UNIX by commercial businesses, the most prominent of which is Sun Microsystems. Additional to certified UNIX computer systems, today Operating system like that of UNIX such example likes BSD products and Linux are regularly come across. UNIX with is pros and cons and besides being a free system, are found as to run on most machine [17].

\subsubsection{Merits of UNIX}

UNIX provides more control by the user. Some OS like Windows and Mac are based on icon and mouse making them more user friendly, user can also activate what the operating system allows. On UNIX, user has no limitation as anything can be done in as much as the operating system offers it.

What it means is that user can work freely without the fear of thinking that the system can be messed up even when the user does not know what he/she is doing. UNIX also can offer both freedom and danger because the operating system can be changed and make more compatible with what one want to do. If one knows what it takes to work perfectly well with UNIX, the operating system can be so powerful that it can be customized, and because it has been in used for a long time, most bugs have been cleared and this fact makes it very reliable.

\subsubsection{Demerits of UNIX}

Successfully usage of UNIX requires that an expert will be needed on site. Simple installation of new products and updates may be difficult if one is not a UNIX expert. Interacting with UNIX system using its command process is difficult, more difficult for a novice, this is why UNIX is most used by sophisticated users. UNIX operating system is a customizable OS, different dialects and languages of UNIX are available in versions.

For example, there was a time Berkley UNIX group were not comfortable with how UNIX classifies users, they had to change the operating system code. Therefore, an expert UNIX user at a domain might face a serious learning curve challenge at another domain or location.

\subsection{Linux Operating System}

The GNU's answer to MAC and also Windows is Linux. Yes, what this means is that Linux is a FREE OS, one can perform 
downloads, modification and also redistribution without any cost. Linux is relatively new in the operating system realm. It was written in the year 1991, and also enhanced for current usage.

Linux and Windows can be compared to an entity that its floor and roof are either replaceable or not. However, with Linux, as an entity, both floor and roof can be moved in any manner as one want, but Windows floor and roof are very rigid that it remains immovable. One cannot go beyond what Microsoft has designed [16, 18].

Linux, designed by Linus Torvalds in the year 1991, heads a group of fresh school open source Unix's that came to be in the year 1990, it also include FreeBSD, NetBSD, OpenBSD, and Darvin. All these is a representation of a design direction that the whole group agreed upon. Linux code is totally different compared to the original UNIX source tree code, however, it uses UNIX standards to behave like a UNIX

Developers in Linux open source community have desires to acquire a substantial share of end-user desktops making Linux's intended users to increase in number than the users of the old-school Unix's, who have fear share desire in the server and workstation market. The aspiration to reach end users made Linux developers much more concerned with ease of installation and in resolving software distribution issues as it was more difficult with UNIX as proprietary systems, applications in Linux are forced to display high degree of ruggedness than their colleagues with proprietary UNIX status.

\subsubsection{Merits of Linux OS}

i. Price: Linux is F-R-E-E. It can be downloaded, installed, used, modified without incurring any cost.

ii. Variety: Linux is nowhere a complete OS but a kernel. The fact that it is a kernel, it requires additional ad-ins in form of software. Many of these kinds of distributions or distros exist.

iii. Virus: The fact that it is open sourced, it is less vulnerable compared with Mac, it does not mean that it's free from virus attack.

\subsubsection{Demerits of Linux OS}

i. Complicated: A good deal of Computer skills are required to use Linux distros even when some of them are quite easy to use.

i. Compatibility: Although Linux has a few percent of the market share like Mac, however, it does not have many programs and games like that of Windows.

ii. Vendors: Linux has very few vendors selling Linux computers, if one needs Linux computer, then it might be that one will need to purchase Windows computer, reformat the hard drive, and then install Linux on it.

\subsection{Macintosh Operating System (MAC OS)}

Mac OS is much older than Windows OS. It was released one year earlier its Microsoft counterpart, and it happens to be the first among other OS, ever successful graphical-inclined OS. Mac OS has undergone basically, two important design transitions, and is on its third stage. The first transition was from supporting only a single application at one time to the ability to cooperatively multitask multiple applications (MultiFinder); the second was the transition from 68000 to PowerPC processors, the third was the coming together of Mac OS design ideas with a Unix-derived infrastructure in Mac OS X.

Mac OS has very high unifying idea significantly different from that of Unix's, this is the Mac Interface Guidelines. These explain a great detail of what an Apps Graphical User Interface is supposed to depict with its expected behavior. One major idea the Mac Interface Guidelines is that everything should stay where they are kept.

Mac operating system apps is termed not huge monoliths. The system's graphic user interface (GUI) support program instructions or codes, which is partly implemented in a ROM conveyed with the hardware and partly implemented in shared libraries, communicates easily with Mac OS software programs through a quite stable event interface. Hence, the operating system design encourages a distinct and clean separation between GUI interface and application engine. Leading-edge Unix's like Linux OS are beginning to borrow ideas like file attributes from Mac OS.

\subsubsection{Merits of Mac OS}

i. Viruses: Apple Macs get almost no viruses. This is because Windows has a very large and superior market share over other OS.

ii. Reliability: Apple computers offers itself for Macs to run only on it, and hence less prone to crashing of hardware and software.

iii. Looks: often time, Mac seems to look better than its counterpart, windows OS.

\subsubsection{Demerits of Mac OS}

i. Expensive: The cost of purchase of Mac is more than that of Windows.

ii. Only available on Apple computers: Already having a computer system that is not an Apple, one will not be able to install MAC in such system. Otherwise, one will need to purchase a new computer system.

iii. Compatibility: Very few programs can only run on MAC OS, likewise computer games.

\subsection{Android Operating System}

The original creator of the platform is Android Inc., Google later bought it over and released the OS as AOSP (Android Open Source Project) in 2007. This new development was complemented by the founding of the OHA (Open Handset Alliance), a consortium saddled with the responsibility to develop and distribute Android. The software, which is now been released under the Apache license is tagged among others, a free open source license. Android releases a new version every few months as a result of the available huge developer communities who regularly updates and create applications using custom-built version of Java.

The OHA group is a consortium of several software, hardware and telecom companies, T-Mobile, Intel, Qualcomm, NVIDIA, HTC, Motorola and Google Inc., for which Android provides their software platform. Their main objective of OHA is to develop available technologies that will considerably lower the cost and time of developing and distributing mobile devices and services. 


\subsubsection{Merits of Android OS}

i. Open Source Platform supported by a wide-range of mobile device manufacturer and communities

ii. Easy access to many free and premium app from communities of Apps developers that support Android OS

iii. Multitasking: Android Operating system has the capability of running many applications and processes within the same available time

iv. Fast and easy notification of SMS, email or RSS reader alert

v. Widget zed home screen allows easy access to settings of phones without wasting time and with ease

vi. The continuous upgrades in appearance and features might shortly leave other iOS far behind soon.

vii. Good for programmers who likes to jumble with Linux Kernel for making alterations in OS.

\subsubsection{Demerits of Android OS}

i. Unstable and disposed to crashes compared to other OS.

ii. Being open source, so many apps are created. Very few of these applications might have bugs which can be abused by hackers or viral infections.

iii. To sign in as administrator for advanced settings, one need to get acquainted with Linux commands.

iv. Frequent updates on the OS could make one upgrade to the latest, and this is called rooting. Rooting should be done carefully, otherwise, one could end up in trouble.

v. Majority of Applications require internet connections for operation which sometimes is a disadvantage.

vi. Poor battery backup management.

\section{6 iPhone Operating System (iOS)}

iOS, which is a mobile OS, is designed and owned by Apple Inc. It was designed and developed for iPhone, but later extended support for iPad and Apple TV. iOS root comes from Mac OS X, hence it is UNIX based OS. Like other OS, iOS is frequently updated starting from iOS version 4.0 and the latest is iOS version 5.1.The Core OS layer resides in the bottom of iPhone OS architecture[19].

Core services layer of iOS architecture encompasses an additional abstraction layer, cocoa touch layer and media. The Core OS layer contain the scheduler inclusively, Mach kernel, file system, hardware drivers and control the memory system, network and inter process communication and security framework to secure the system and program data. As confirmed that the core services layer of the OS has an abstraction setup. It also contain nonstop accessibility to the network availability, basic framework for objective-C programming, state of mobile device, access to location information and address book. As of March 2012, 550,000 iOS apps are available in Apple store (Anup, Raman et al 2015). iOS has many benefits and non-benefits as stated below.

\subsubsection{Merits of $i O S$}

i. Stable and safe Operating System for mobile phones

ii. Probably the most loved interface for any mobile OS in the market. Good looking designed desktop and app icons which go hand to hand with the stunning looks of Apple devices.

iii. Minimal viruses and safe OS with the consideration of very high standard when applications were developed and when updates were also made.

iv. High adherence to current web standard and procedures.

v. High consideration for cloud storage technology.

vi. Easy access to free and premium apps from Apple store.

\subsubsection{Demerits of iOS}

i. iOS only support Apple Hardware, and less operability

ii. Very costly

\section{DEDUCTIONS}

a. Windows 10 had 0.04 malware file present while Windows 7 machine was 0.08 .

b. Higher $\%$ of mobile malware target Androids than iOS.

c. Windows 10, Linux, UNIX and Mac OS are more secured and reliable.

d. Windows and Android are more popular, userfriendly, easy to use and allow more application program than Mac OS.

e. Linux and Android are free while Windows is moderately costly and Mac OS highly costly.

f. Except for Mac and iOS others allow compatibility. Windows 10 and Mac OS integrated firewall.

g. The comparative analysis and market share analysis between August 2018 and June 2020 showed that Android and Windows OS are very high compare to other OS. Android and Windows has $38.3 \%$ and $36.55 \%$ respectively (See Table 2 )

Table 2. Operating System Market Share Worldwide (gs.statcounter)[20]

\begin{tabular}{|c|c|c|}
\hline Operating Systems & $\begin{array}{c}\text { August 2018 } \\
(\mathbf{\%})\end{array}$ & $\begin{array}{c}\text { June 2020 } \\
(\mathbf{\%})\end{array}$ \\
\hline Android & 41.8 & 38.3 \\
\hline Windows & 35.8 & 36.55 \\
\hline iOS & 13.49 & 14.3 \\
\hline OS X (UNIX) & 5.45 & 8.35 \\
\hline Linux & 0.77 & 0.88 \\
\hline Other & 1.74 & 1.83 \\
\hline
\end{tabular}




\section{CONCLUSION}

Windows and Android tend to be the most widely used especially the newest versions. It is because they are affordable, secured, reliable, compatible and friendly. It could be concluded that every operating system, with a particular direction, was developed by considering targeted customers and their interest. Every Operating System, mobile OS inclusive, provides competitive and distinct features and services for their customers. However, all open sourced Operating Systems enjoys addition of new ideas, in applications and updates every day by various community developers, this also enhanced their security features and performance, while the enterprised OS lacks flexibility of design. This will not underscore the fact that every OS is good, but users' choice depends on the services required of it.

\section{ACKNOWLEEMENT}

Thanks to everyone who contributed to the completion of this research work especially Prof B. Akinnuwesi.

\section{REFERENCES}

[1] A. Silberschatz, P. B. Galvin, and G. Gagne, Operating System Concept, S. Ken, ed., pp. 1-3, USA: John Wiley \& Son Inc., 2009.

[2] F. Lin, and W. Ye, "Operating system battle in the ecosystem of smartphone industry," in 2009 international symposium on information engineering and electronic commerce, 2009, pp. 617-621.

[3] T. V. Chien, H. N. Chan, and T. N. Huu, "A comparative study on operating system for wireless sensor networks," in 2011 International Conference on Advanced Computer Science and Information Systems, 2011, pp. 73-78.

[4] A. R. Mudiraj, "Windows, Linux and Mac Operating system Booting Process: a Comparative Study," International Journal of Research in Computer and Communication Technology, vol. 2, no. 11, pp. 2278$5841,2013$.

[5] T. Sharma, M. K. Beniwal, and A. Sharma, "Comparative study of different mobile operating systems," International Journal of Advancements in Research \& Technology, vol. 2, no. 3, pp. 1-5, 2013.

[6] M. S. Ahmad, N. E. Musa, R. Nadarajah, R. Hassan, and N. E. Othman, "Comparison between android and iOS Operating System in terms of security," in 2013 8th International Conference on Information Technology in Asia (CITA), 2013, pp. 1-4.

[7] O. Okediran, O. Arulogun, R. Ganiyu, and C. Oyeleye, "Mobile operating systems and application development platforms: A survey," International journal of advanced networking and applications, vol. 6, no. 1, pp. 21952201, 2014.

[8] C.-F. Chien, K.-Y. Lin, and A. P.-I. Yu, "Userexperience of tablet operating system: An experimental investigation of Windows 8, iOS 6, and Android 4.2," Computers \& Industrial Engineering, vol. 73, no. 1, pp. 75-84, 2014.
[9] P. Kaur, and S. Sharma, "Google Android a mobile platform: A review," in 2014 Recent Advances in Engineering and Computational Sciences (RAECS), 2014, pp. 1-5.

[10] D. Patil, and B. Meshram, "Forensic investigation of user activities on Windows7 and Ubuntu12 operating system," International Journal of Innovations in Engineering and Technology, vol. 5, no. 3, pp. 58-66, 2015.

[11] V. Rema, and M. KirthiVasan, "Determinants affecting the choice of Mobile Operating System among Smartphone Users: A Comparative study of Android vs. iOS in Bangalore," Management Review-A Research \& Academic Journal of Business Management, vol. 6, no. 2, pp. 22-26, 2015.

[12] N. Ahmad, M. W. Boota, and A. H. Masoom, "Comparative analysis of operating system of different smart phones," Journal of Software Engineering and Applications, vol. 8, no. 03, pp. 114-126, 2015.

[13] A. Fernandes, and J. Tribolet, "Enterprise Operating System: the enterprise (self) governing system," Procedia Computer Science, vol. 164, no. 1, pp. 149-158, 2019.

[14] R. Kouki, A. Boe, T. Vantroys, and F. Bouani, "Autonomous Internet of Things predictive control application based on wireless networked multi-agent topology and embedded operating system," Proceedings of the Institution of Mechanical Engineers, Part I: Journal of Systems and Control Engineering, vol. 234, no. 5, pp. 577-595, 2020.

[15] H. Nair, and R. Sridaran, "An Innovative Model (HS) to Enhance the Security in Windows Operating System-A Case Study," in 2019 6th International Conference on Computing for Sustainable Global Development (INDIACom), 2019, pp. 1207-1211.

[16] M. M. Chim, M. V. Rathod, and M. P. Chawan, "Linux \& Windows Operating Systems," Journal of Engineering, Computers \& Applied Sciences (JEC\&AS), vol. 2, no. 6, pp. 15-20, 2013.

[17] J. Viega, and J. Voas, "The pros and cons of Unix and Windows security policies," IT Professional, vol. 2, no. 5, pp. 40-47, 2000.

[18] W.-C. Fan, C.-S. Wong, W.-K. Lee, and S.-O. Hwang, "Comparison of Interactivity Performance of Linux CFS and Windows 10 CPU Schedulers," in 2020 International Conference on Green and Human Information Technology (ICGHIT), 2020, pp. 31-34.

[19] A. Naseer, W. B. Muhammad, and H. M. Abdul, "Comparative Analysis of Operating System of Different Smart Phones," Journal of Software Engineering and Applications, vol. Vol.8 no. No.3, pp. 114-126, March 2015,2015

[20] Https://gs.statcounter.com/os-market-share 